\title{
Una reflexión sobre la des-esclavización y los elementos teóricos y metodológicos de esta perspectiva*
}

Francisco Uriel Zuluaga Ramírez

\begin{abstract}
Resumen
Este artículo trata de mostrar la línea general del desarrollo de los estudios afrocolombianos desde una perspectiva histórica, para hacer patente la necesidad de obtener un paradigma que sirva de referente a una concepción de estos estudios desde la mirada afro y afrodescendiente desde un horizonte africano en su desenvolvimiento diaspórico para la conservación cultural de los afrodescendientes.
\end{abstract}

Palabras Claves: afrodescendientes, diáspora, transculturación, esclavitud.

\section{Abstract}

This article tries to show the general line of development of Afro-Colombian studies from a historical perspective, to make patent the need for a paradigm that serves as a reference to a conception of these studies from the perspective of African and African-American from the African horizon diasporic development for cultural preservation of African descent.

Keywords: Afro, diaspora, transculturation, slavery.

La pretensión de proponer nuevas escrituras de la historia de las sociedades negras, del valle del Río Cauca, es el intento de cumplir un deseo, expresado por muchos de los tratadistas de los problemas afro-americanos desde los comienzos de su develamiento académico por parte de los historiadores y otros científicos sociales. Ya en, o quizá sólo hasta, 1906 un estudioso francés se extrañaba de la escasa atención prestada por los historiadores al estudio de la esclavitud (Scelle, 1906, p. 1). Pero tal desinterés no era exclusivo de Francia o de Europa. Aquí, en Colombia, escenario de tal institución, fue necesario esperar medio siglo más para que los estudios afroamericanos hicieran su aparición, mediando un período de desarrollo de esta clase de investigaciones en el Caribe, fundamentalmente en Cuba, durante el cual, los llamados precursores por Jaime Jaramillo Uribe (Jaramillo, 1986), sentaron bases para los estudios afrocolombianos. Una relectura hace evidentes los elementos con que contribuyeron al método, el análisis y el establecimiento del sentido de los estudios afro-americanos y afrocolombianos.

\footnotetext{
*Artículo tipo 3: de revisión según Colciencias.

${ }^{* *}$ Historiador - Profesor jubilado Departamento de Historia, Universidad del Valle - Master of Arts in History, Vanderbilt University - Doctor Honoris Causa en Historia, Universidad del Valle, Cali. Miembro del grupo de investigación Cununo, reconocido por Colciencias en Categoría D. E-mail:

fzuluaga2@gmail.com.
} 
El primero de ellos, Don Fernando Ortiz (1881-1969), en su afán de descubrir la cubanidad (Ortiz, 1999, p. 473.), nos legó un instrumento incuestionablemente importante en la tarea de comprender los procesos sufridos por los pueblos sometidos a otros que, al no reconocerlos iguales, procuran desaparecerlos, ignorarlos u ocultarlos como seres humanos. Este instrumento intelectual fue el concepto de transculturación, tan importante como que se ha hecho de forzosa utilización, así se procure desautorizar a Ortiz desde novísimas miradas de lo étnico en América.

El segundo señalado por Jaime Jaramillo Uribe fue José Antonio Sacco (17971879) quien, con sus obras Historia de la esclavitud de los indios en el Nuevo Mundo (1932) y la Historia de la esclavitud de la raza africana en el Nuevo Mundo y en especial en los países Américo-hispánicos (1932), —ambas inconclusas y aún así constan de cuatro volúmenes - dio un paso importante en mostrarnos muchas dimensiones del estudio de la esclavitud en la historia de la humanidad.

Lo mismo podrá decirse de Manuel Moreno Fraginals (1920-2001), quien años más tarde en su libro La historia como arma (1980), no sólo se incorporó al debate sobre transculturación proponiendo la recomposición del concepto en la díada aculturación - deculturación; sino que también expresó algunas dificultades del historiador en su búsqueda de un pasado basándose en documentos escritos u orales y su examen con los procedimientos e instrumentos de la investigación histórica.

Dice Moreno Fraginals:

En las fuentes documentales que consulta (el historiador) encuentra su primera extraordinaria dificultad. Puede afirmarse que la casi totalidad de los documentos con que trabaja el historiador se originaron en las clases sociales dominantes. Ahora bien, en un lógico proceso defensivo estas clases dominantes han ido depurando sus documentos, borrando -como los delincuentes- las huellas de sus pasos y dejándonos, como fuentes históricas, un material previamente seleccionado y con el cual sólo puede llegarse a ciertas conclusiones prefijadas.

La historia escrita de Cuba - no hablamos de historia real- es un ejemplo concreto de cómo se han manejado los documentos y organizado el conjunto de mitos que constituyen nuestra superestructura histórica.

A los fines de este trabajo basta señalar sólo algunos puntos que constituyen dogmas fundamentales, como, por ejemplo, el antiespañolismo, el escamoteo del problema negro y la presentación de la burguesía como grupo creador de la nacionalidad. (Moreno, 1983, p. 17)

Así, en el ámbito externo a nuestro país y desde el comienzo de los estudios afroamericanos, se hizo evidente la necesidad de aceptar con mucha reserva una información escrita por el esclavista, en detrimento de la imagen y el 
reconocimiento de la población y la cultura de los seres humanos arrancados de África y sus descendientes en América.

Simultáneamente, quizá sin la claridad que posteriormente nos entregó Claude Meillasoux, (Meillasoux, 1990.) se percibía que la esclavitud moderna presentaba características tendientes a disolver la cultura ancestral de los negros y acondicionarlos a existir como cosas, mercancías y seres infrahumanos, mediante procesos deculturadores - aculturadores que facilitaran el producto final pretendido: el esclavo.

Aunque es general el acuerdo de que la investigación sistemática de la población afrodescendiente colombiana se inició con el padre José Rafael Arboleda S.J. (1952), no puede dejar de anotarse el entusiasmo con que desde la década de 1930 se publicaron los trabajos de Eduardo Posada (Posada, 1933) y Carlos Restrepo Canal (Restrepo, 1933) y Gregorio Hernández de Alba. (Hernández de Alba, 1956).

El primero de estos tres presenta un escrito descriptivo de la esclavitud en el territorio colombiano, siguiendo su desarrollo legal; el segundo ofrece una compilación de la legislación relativa a la institución esclavista, desde la Real Cédula de 31 de mayo de 1789 hasta el Decreto de junio 21 de 1842 sobre formación anual del censo de los esclavos; estos dos libros fueron publicados en oportunidad del centenario de Don José Félix de Restrepo.

El antropólogo Gregorio Hernández de Alba publicó su ensayo, en 1956, para llenar el vacío y la ignorancia que había rodeado la celebración del Centenario de la "Abolición de la esclavitud", despreocupación que atribuye al clima político de la época y aprovechó la oportunidad para entregar su balance bibliográfico, en los siguientes términos:

Pero era que en ese tiempo la libertad sufría un eclipse; gritar su nombre era en muchos sitios llamar la muerte. Por ello muy poco se acreció entonces la corta bibliografía colombiana sobre tal tema, del cual apenas si podrían citarse pocos títulos, los más de colaboraciones en revistas, de pocos discursos, de alusiones en novelas de distintas épocas como "La María", "El Alférez Real", "Como se hace ingeniero un negro en Colombia", por Manuel Baena; "Cantos populares de mi tierra" por Candelario Obeso; "Historias y leyendas de Cartagena", del doctor Arcos; y varias de estos últimos años: "Risaralda", de Bernardo Arias Trujillo, "Las estrellas son negras" de Alfonso Palacio, "Tambores en la noche", de Jorge Artel, "Tierra Mojada", "Pasión Vagabunda", y "He visto la noche de Manuel Zapata Olivella, y "Las memorias de odio" de Rogelio Velásquez. (Hernández de Alba, 1956, p. 9.)

En este ensayo de apenas 78 páginas, Hernández de Alba toca casi todos los temas que cubren los estudios de negros. Pero lo más sugerente es el concepto de esclavitud que presenta. 
Las definiciones de esclavitud siempre se habían construido desde el criterio jurídico de sometimiento total de un ser inferior a otro superior, por naturaleza o por la gracia de Dios o desde el punto de vista económico donde, por transacción legitima un hombre, el tratante de esclavos, vendía a otro hombre una cosa, adquiriendo sobre ella (el esclavo) todos los derechos que le permiten disponer de la vida, honra y bienes del objeto adquirido. (Posada, 1933; Finley, 1982)

Hernández de Alba, no mira el problema desde la simple acción jurídica o económica, aborda la esclavitud desde el significado que el sometimiento representa para el negro esclavizado:

La esclavitud no significó únicamente tener hombres forzados a su servicio, sino mucho más; ella implicaba el extrañamiento de seres humanos de su tradicional hábitat, de su cultura, de sus lenguas, de sus religiones, de su aceptada organización social y política y de sus oficios. (Hernández de Alba, 1956, p. 22.)

Esta nueva percepción socio-cultural de la esclavitud, por arte de birlibirloque no recibió en su momento la atención debida, permitiendo, a mi parecer, un retraso notable en los estudios culturales tanto de las comunidades afrodescendientes en Colombia como de los efectos de la diáspora en su diseminación cultural en América.

Sin embargo, la mayor parte de las investigaciones posteriores, han venido utilizando la concepción que entiende al esclavo como cosa. Sólo mas adelante, en la medida en que la historia se vaya abriendo a miradas más antropológicas o los trabajos sociológicos y antropológicos perciban la diacronía en que se desenvuelven estas culturas, concepciones como la enunciada por Hernández de Alba aportarán sus luces al tema afrocolombiano.

Un estudio importante fue el realizado por James Ferguson King, Negro Slavery in the Viceroyalty of New Granada, tesis doctoral defendida en 1939. Ha sido de escaso influjo en la producción posterior, quizá por no haber sido publicada. Sin embargo, conocida por los expertos, marca algunas directrices para los historiadores más inmediatos cuya preocupación privilegia el estudio de la trata y el problema jurídico de la esclavitud.

A esta altura, debo recordar que hace unos años ya reflexionaba sobre el asunto, entregando opiniones que hoy vuelven a ser validas. Decía entonces que, sin pretender la profundidad del balance realizado por el maestro Jaime Jaramillo Uribe (Jaramillo, 1986) ${ }^{1}$, creo que se puede afirmar que los estudios sobre negros en Colombia, además de estar aislados de las grandes corrientes latinoamericanas —en este caso dominadas por los estudios sobre el Caribe-

\footnotetext{
${ }^{1}$ Un extraordinario balance de este tópico fue presentado por el maestro Jaime Jaramillo Uribe al primer "Seminario Internacional sobre la Participación del Negro en la Formación de las Sociedades Latinoamericanas", realizado en Bogotá en 1986, cuya edición estuvo a cargo de Alexander Cifuentes.
} 
presentan una división tajante entre las áreas trabajadas por historiadores y las trabajadas por otros científicos sociales.

Tan alejados hemos estado de las corrientes internacionales que, mientras en Cuba aparecieron los primeros estudios de Fernando Ortiz en la primera década del siglo XX, sólo en 1952 el padre José Rafael Arboleda empezó a promover los estudios afrocolombianos (Jaramillo, 1986, p. 44) y en un balance de la producción sobre esclavitud negra y abolición en Latinoamérica, entre 1971 y 1979, publicado por Magnus Mörner (Mörner, 1979), _sólo aparecen reseñados dos autores colombianos (Jaime Jaramillo Uribe y Gērmán Colmenares) y dos autores extranjeros con investigaciones sobre Colombia (William F. Sharp y Michael Taussig). Pero, además, mientras los historiadores se han reservado para sí el estudio de la trata negrera, los estudios económicos de la esclavitud y de su abolición, (Palacios, 2973; Colmenares, 1979; Sharp, 1976.)_Los antropólogos, lingüistas y sociólogos se han dedicado al estudio de las relaciones sociales y de las manifestaciones culturales. (Friedemann, 1974; Gutiérrez de Pineda, 1963; Fals Borda, 1980.).

En medio de este compartimentalismo del trabajo, sólo tres autores han hecho esfuerzos por mirar los problemas negros como una totalidad con múltiples manifestaciones: Aquiles Escalante, Jaime Jaramillo Uribe y Nina de Friedemann. El primero, Aquiles Escalante, es el pionero de los estudios negros que, inaugurando la visión antropológica de El Negro en Colombia se ve obligado a trazar —en líneas generales- el proceso histórico de su objeto de estudio. (Escalante, 1964; 1954.) Jaime Jaramillo Uribe es el maestro de toda una generación de historiadores que, examinando desde todos los ángulos y trazando derroteros, muestra todas las facetas del problema, tanto en su dimensión económica, como en las relaciones sociales y los debates jurídicos acerca de la esclavitud (Jaramillo, 1968). ${ }^{2}$ Y Nina de Friedemann, a través de estudios antropológicos sobre negros del Atlántico y del Pacífico, de sus formas de vida y de sus formas de resistencia, y con un ánimo reivindicatorio del negro, ha ido acercándose a una visión diacrónica del problema antropológico que se propone (Friedemann, 1986; 1979).

Pero, el distanciamiento entre historiadores y otros científicos sociales no es gratuito, obedece al valor que se le da a la diacronía y a la sincronía. Mientras los demás científicos sociales se preocupan -fundamentalmente-por el presente, construyen visiones sincrónicas en las que el pasado suele estar presente en descripciones rápidas y superficiales que acostumbran presentarse como capítulos titulados "Antecedentes Históricos". Los historiadores, por su parte, preocupados fundamentalmente por el fluir de los acontecimientos en el tiempo, tienden a desconfiar de los trabajos sincrónicos y a negarse su acceso al presente, con la disculpa de que es necesaria una distancia prudencial —en el tiempo- que permita la objetividad y la imparcialidad científicas.

\footnotetext{
${ }^{2}$ Inicialmente publicados en el Anuario Colombiano de Historia Social y de la Cultura y más tarde editados en este volumen.
} 
El debate sobre estas posiciones es amplio y seguramente continuará. Pero al margen y por encima de él, hay temas que van obligando a revisar tales posiciones, $y$, en el caso de los negros el tema que ha obligado a los científicos sociales a considerar la diacronía, y a los historiadores a avanzar hacia el presente, es el de las relaciones sociales, especialmente las relaciones conflictivas.

Los estudios históricos sistemáticos sobre los afrocolombianos dilataron su aparición hasta 1952 cuando José Rafael Arboleda (1916-1992) público su artículo "Nuevas investigaciones afrocolombianas" en la Revista Javeriana. (Arboleda, 1952). Este artículo sugirió métodos y un programa de investigación de los problemas afrocolombianos y fue ponderado por Meville J. Herskovits, de la Northwestern University (Evanston, Illinois), de quien fue alumno. Siguiendo los principios de abandonar la etnología pura y propender por una etnología experimental, como proponía Herskovits, ${ }^{3}$ y guiarse por “...un concepto dinámico de la Cultura, la cual, ya sea por fuerza propia, o por el contacto de otra que la circunda o se le acerca va modificándose, razón por la cual las raíces de las culturas se conocen mejor por el contacto cultural, o aculturación...”.(Arboleda, $1952,197)$ Como desarrollo de este principio, aconseja no preconcebir que el indígena y el negro se sometieron totalmente a la cultura española, tener presente que una descripción de las costumbres de los pueblos africanos es básica para el conocimiento de una tradición subconsciente en los descendientes africanos de hoy, y seguir las tres leyes básicas de Herskovits:

1.- La ley de la retención, evidenciada en dos manifestaciones: Sincretismo y Reinterpretación.

2.- La ley de la aceptación de elementos nuevos

3.- La ley del Foco Cultural. (Arboleda, 1952, 201)

Finalmente, después de estos consejos metodológicos, utilizando ejemplos, propone desarrollar programas investigativos que comprendan todos los aspectos desde una perspectiva sociológica pero iluminado permanentemente por la búsqueda del conocimiento de la Cultura.

Thomas Price Jr., en 1954, hizo un amplio diagnostico publicado por el Instituto Colombiano de Antropología, titulado Estado y Necesidades de las Actuales Investigaciones Afrocolombianas. En él Price aprecia el panorama de los estudios afrocolombianos desde el punto de vista de la Antropología y los principios de Hercovitz. Desde tal perspectiva afirma una apreciación general acerca del sentido de estas investigaciones:

A través de un conocimiento creciente de las culturas de las cuales originaron los esclavos, de las diferentes pautas de costumbres coloniales a las cuales fueron trasplantados, de los factores de aculturación que allí operaban y de las

\footnotetext{
${ }^{3}$ En el texto de Arboleda es notoria la influencia de Hercovitz, cuyas características abordaremos unos párrafos adelante, a propósito de un artículo de Thomas Price Jr.
} 
culturas actuales del Negro en el Nuevo Mundo, se gana la comprensión de los procesos subyacentes a los cambios culturales y se avanza hacia los objetivos de la antropología contemporánea. (Price, 1954, p. 13.)

La apreciación de Price, sobre el caso de los estudios colombianos, es la de que - para entonces - la escasez de investigaciones y la variación de las "pautas culturales observadas a través de las diferencias culturales" entre la Costa Atlántica y la Costa Pacífica, ofrecen oportunidades extraordinarias que "rigen los cambios culturales". A renglón seguido el cuerpo del artículo es una fina mixtura de sus observaciones, las observaciones de otros investigadores y los consejos prácticos y puntuales para otros investigadores.

Por aquellos tiempos, presentaron sus respectivos trabajos iniciales Aquiles Escalante y Rogelio Velásquez. El primero, en su trabajo El Negro en Colombia, (Escalante, 1964) siguiendo las pautas del padre Arboleda y de Price, deslumbrado por las posibilidades innúmeras que se abrían para avanzar y dilatar los estudios afrocolombianos, nos introduce en la trata intercontinental de esclavos, procura establecer los orígenes tribales, discute el concepto de esclavitud, la resistencia a la esclavitud, y también las manifestaciones culturales del negro. Es como si quisiera hacer del libro una vitrina invitando a los antropólogos a escoger tema. Los métodos y el compromiso social se plantean en otros trabajos, en los que se muestra como precursor. En Palenque de San Basilio, (Escalante, 1954) no sólo descubrió una comunidad y una cultura para la reflexión académica, además corroboró la necesidad de impulsar el trabajo de campo y el compromiso del investigador con los núcleos humanos que estudia. En La minería del hambre (Escalante, 1971) mira la explotación del negro chocoano por empresas extranjeras y se revela ante las injusticias pasando, en algunas oportunidades, de la descripción a la denuncia. El segundo, Rogelio Velásquez, con enorme capacidad descriptiva se muestra como un observador polifacético que encuentra dignos de estudio; la historia del Chocó, las costumbres de su gente, las prácticas rituales en torno a la enfermedad y a la muerte. Aunque poco se deja tentar por la interpretación, es necesario reconocer la importancia que da a los elementos tradicionales y religiosos en la comprensión de la vida de los afrodescendientes del Chocó. Una, entre múltiples consideraciones que nos ha legado es la siguiente:

Antiguamente a los considerados brujos se les hendía el pecho y el estómago con macanas filudas para que no se levantasen a dañar a sus enemigos. El cristianismo ha desalojado esta costumbre, lo mismo que la de sepultar debajo de las habitaciones. Cuando esto ocurre, como en el caso de la familia Ceballos, de Mumbú, se derriban los tambos y se abandona la comarca. (Velásquez, 2000, p. 154).

Por estas calendas aparece Manuel Zapata Olivella quien propone incorporar a los estudios afroamericanos la "creatividad del negro bajo la opresión". (Zapata Olivella, 1989, pp. 96 - 123). Esta creatividad, puesta en práctica en mecanismos religiosos de defensa, es el fundamento de su capacidad para conservar la cultura 
bajo la opresión y modela sus conductas, impregnadas de religiosidad en todos los aspectos de la vida.

En la medida que avanzan los estudios sobre las culturas orales africanas, nos es dado explicarnos los patrones tradicionales que guiaron a sus pueblos en el exilio y que les permitieron sobrevivir y mantenerse espiritualmente unidos a pesar de las distancias geográficas, las barreras lingüísticas y las condiciones infrahumanas de la esclavitud. (Zapata Olivella, 1993, p. 167).

Todo ello logrado gracias al Muntu africano, una filosofía tradicional africana que bien podría servirnos en nuevos análisis asumiéndolo como un concepto africano para estudiar las sociedades afro-americanas.

Aplicando el concepto al tambor, y a guisa de ejemplo, Esteban Cabezas nos dice:

Este tambor tan propio y tan íntimo, que no llegó a América en las barcas, filibotes o galeones de dolor, sino con los negros plagiados de su África natal, que al establecerse en este otro trópico lejano, lo construyó a imagen y semejanza de los auténticos, gracias al Muntu que lo iluminó con la memoria de la nostalgia. (Cabezas, 1993, p. 279)

Un tema problema, señalado desde años atrás, requirió del valor y la tozudez de Nina de Friedeman para colocarlo en la palestra como debate académico y público: el ocultamiento del negro. Varios trabajos suyos se dedicaron a denunciar las formas evidentes de discriminación, marginalización y sometimiento de los afrocolombianos, que quedaban en una especie de impunidad socio-cultural mediante el procedimiento de la invisibilización.

Escribió en abundancia, en libros y en revistas, siempre desde una perspectiva cultural, desentrañando las estructuras fundamentales de las comunidades como en la minería, (Friedemann, 1974) analizando sus expresiones artesanales, mostrando las "huellas de africania", siguiendo el proceso histórico y la presencia del negro en Colombia; sintetizando y denunciando la situación marginal y de invisibilidad del negro, como lo hace en La saga del negro. (Friedemann, 1993)

Algunas de sus obras las publicó acompañada por Jaime Arocha, quien además emprendió con ella varios programas de investigación y divulgación como: La Antropología en Colombia, La expedición humana, la Revista el Negro en Colombia. Contribuyó en la gestión, ante la Constituyente de 1961, del transitorio 51 y luego en la Ley 70 de 1993, el más importante logro étnico de los afrodescendientes en el orden institucional.

Esta ley ha tenido muchos altibajos en su ejecución, pero, en lo atinente a esta reflexión debemos señalar que, además de un revuelo político por su puesta en marcha, sacó a flote un sentido identitario en el grueso de la población y despertó mucho interés en los sectores intelectuales, donde cada vez es más notoria la presencia de estudiosos afrocolombianos. La ley, al condicionar el reconocimiento 
de las comunidades a la demostración de su presencia material y cultural en territorios ancestralmente ocupados con ejercicio de soberanía y territorialidad, impulsó la realización de investigaciones de tendencia etnográfica y etnohistórica.

Durante este proceso, se debió acudir a nuevas teorías y concepciones de esclavitud que habían mostrado su pertinencia en otras latitudes. Una de ellas me incitó a ponerla en práctica en mis reflexiones; ella se presenta y explica en el libro Antropología de la Esclavitud de Claude Meillasoux (Meillasoux, 1990).

Varios son los aportes de Meillasoux al estudio general de la esclavitud que, bien entendidos y atendidos, nos ayudan a pensar la historia de los afrodescendientes de una forma distinta a la tradicional.

Empieza por hacernos patente cómo, para un estudio social de la esclavitud, es necesario superar las definiciones de la misma acudiendo a una mirada histórica de su proceso, y a renglón seguido nos descubre la esclavitud como carencias o negaciones de la condición humana del esclavizado. Todo ello nos servirá para, más delante, discutir sobre la libertad supuestamente otorgada a los esclavos y señalar el proceso de abolición de la esclavitud como una farsa.

Debemos traer a la memoria el período de descubrimiento y conquista de América y recordar que, por aquel entonces, se discutió sobre la capacidad de los aborígenes de América para llegar ser súbditos de su Majestad el Rey de España, debate que luego se extendió a los naturales de África bajo la modalidad de averiguar si ellos podían ser sometidos a esclavitud en América; lo cual se resolvió a partir del reconocimiento de su posesión de alma, mediante la cual se les reconocía la certeza sensible. Todo ello entendiendo que para la tradición cristiana el intelecto,

“...estaba dividido en tres grados de certidumbre: la certeza sensible, por medio de la cual el mundo exterior era conocido, la certeza moral, que le daba a cada hombre la capacidad de diferenciar el bien del mal y la certeza sobrenatural, que relacionaba a determinados hombres con Dios y les daba la capacidad de gobernar". (Barona, 1993, p, 39).

Es decir que, en última instancia, existían hombres que, poseyendo la certeza sobrenatural y las otras certezas, estaban destinados a dirigir y gobernar sobre los otros hombres; otros que carecían de la certeza sobrenatural pero tenían la certeza moral y la sensible, estaban destinados a los trabajos de la producción y a las artes que requerían distinguir entre el bien y el mal bajo el gobierno de otros; y, finalmente, unos últimos escasamente tenían la capacidad para distinguir aquello que podía percibirse a través de los sentidos, dedicándose a trabajos mecánicos, prácticamente sin discernimiento alguno, casi como animales.

Las definiciones de esclavo en términos jurídicos y económicos, que han sido las de mayor circulación, presentan al esclavo como un hombre con limitaciones jurídicas o económicas específicas. En el caso jurídico se lo define como "cosa" 
que no alcanza la condición de persona y que por tanto no tiene existencia legal más allá de ser una extensión, como objeto de propiedad, de su dueño. Desde el punto de vista económico se lo reduce a la condición de mercancía. (Finley, 1982; Meillasoux, 1990; Palacios, 1988).

Aunque ambas definiciones se refieren a una calidad de hombres, lo que se afirma de ese hombre específico son características negativas. La definición política le niega su condición de persona y sujeto de derecho aunque objeto del mismo, tal situación hace al esclavo inexistente jurídicamente en términos de la carencia de derechos y obligaciones aunque como cualquier cosa sea objeto de los derechos señalados para las personas jurídicas.

Esta consideración es base necesaria para que desde el punto de vista económico, aunque mencionándolo también como hombre, se le llegue a considerar susceptible de enajenación e intercambio al igual que cualquier mercancía, y por lo tanto bien de libre disposición del amo. De esta manera, las dos definiciones cumplen la finalidad de definir a un tipo especial de hombre concluyendo en la negación de sus condiciones de tal.

Ambas definiciones parecen ser universales cuando hablan de su objeto en términos intemporales, desconociendo la posibilidad de ser o llegar a ser un hombre completo. Es decir que, sin dar razón alguna, realizan el malabarismo de definir a un hombre por su condición de no-hombre y sin mencionarlo para nada, lo que se reconoce de Él no es la posesión limitada o no de las tres certezas sino la carencia de ellas o, cuando mucho, su posesión de la certeza sensible.

Pero la dimensión humana de la esclavitud solamente es perceptible cuando de ella se habla en términos sociales y, como lo hace Meillasoux, se acepta que si bien por principio ese hombre no deja de serlo, el hecho de sujetarlo en esclavitud, de inmediato está provocando la negación, el despojo de una serie de cualidades que lo dejan no solo reducido a cosa, también procuran aculturarlo de tal manera que sienta tal estado como su estado natural.

Indica Meillasoux que, al hacer esclavo al hombre, se lo: Desarraiga, Despersonaliza, Desocializa, Desciviliza, Desexualiza, se le hace extraño.

El efectivo meollo de la esclavitud como una relación social sólo se encuentra cuando se establecen las negaciones que, para el ser humano, representa su sometimiento a la esclavitud. Como bien lo señala Claude Meillassoux en su ensayo teórico de Antropología de la Esclavitud:

...la historia de la esclavitud en África se muestra indispensable para captar la significación de los hechos que la acompañan: la historia es la que pone en evidencia la especificidad del modo de reproducción esclavista, le da sentido a la economía guerrera y aporta el medio para interpretar algunas de las formas de poder. Muestra que el fenómeno esclavista se inscribe en un complejo social y político de un alcance geográfico considerable. La dimensión 
antropológica sólo tiene significación en ese contexto, el cual remite a su vez a la economía y a la demografía del conjunto de los pueblos implicados: los que han sufrido los raptos y los que se han beneficiado con ello. (Meillasoux, 1990, p. 24).

Es el proceso histórico el que pone en evidencia, para la teoría de la esclavitud, cómo el origen de ella no se da en la pérdida de una libertad, sino en la privación de un parentesco seguida de la negación, al hombre objeto de la esclavitud, de su condición de pertenencia a un grupo, haciéndolo extraño al grupo y al espacio en que reside; desocializándolo por el impedimento de constituirse como grupo social organizado; despersonalizándolo por su asimilación a una extensión del amo; desexualizándolo por la negación, no de su capacidad de reproducción biológica, si no por el impedimento del ejercicio de las funciones propias de cada sexo en relación con su cría; y finalmente, descivilizándolo al negarle toda posibilidad de participación activa en una sociedad civil. (Meillasoux, 1990).

Precisamente, por las características anteriores, cuando al esclavo, en el proceso de la historia de la esclavitud americana, se le otorga la libertad, no se le está restituyendo a una condición que niegue la esclavitud, se está creando la imposibilidad de la sujeción física y material de un individuo por otro y, cuando en la ley de libertad de esclavos se le posibilita el llegar a ser ciudadano, de ninguna manera se le re-socializó, se le retornó a la condición de persona humana o se le dejó de hacer extraño. En rigor, la libertad concedida a los esclavos sólo permitió la desaparición del término "esclavo" y reconocerlo como ser no sujeto a la condición de cosa o semoviente, además se le categorizó como ciudadano en una sociedad donde, para que tal título estuviera vinculado a la participación en las decisiones electorales, era necesario saber leer y poseer algún capital, de lo que carecía el esclavo y que tampoco se le facilitaron al otorgarle la fementida "libertad" para su calificación de tales. Pero las condiciones sociales continuaron, si no intactas si actuantes, y bien pudiera decirse aún pervivientes. Quizá el aparato institucional actuó de buena fe al proclamar una libertad dentro de los parámetros político-judiciales del sector social dominante, lo cierto es que lo que habría significado libertad para el esclavo era la recuperación de lo que había sido despojado al momento de hacerlo preso en África y que se le seguía negando a sus descendientes.

El negro esclavo siempre se resistió a la esclavitud, para ello adoptó múltiples formas, tanto de resistencia activa como de resistencia pasiva, o la utilización de los recursos legales que el sistema esclavista les brindaba.

Es a la luz de esta concepción de la esclavitud, presentada por Meillasoux, que se comprende y redimensionan los conceptos de aculturación y deculturación propuestos por Fernando Ortiz y Manuel Moreno Fraginals. Es aquí cuando queda claro que la esclavización era un proceso mediante el cual se buscaba transformar al hombre en cosa y que además se lo creyera. 
La liberación de los esclavos en América Española, como en el caso de la actual Colombia, no provino sólo de una decisión cultivada y amasada íntimamente por los negros, como un rechazo a la esclavitud, sino que en ella también actuaron factores de agitación provenientes del mundo de los esclavistas. En general, la única libertad que la población esclava de la Nueva Granada había conocido, era la que observaban en la vida diaria de los indios y los mestizos. Para los negros la interiorización de la liberación los condujo a posturas radicales que se expresaron en el deseo de construir palenques, en el amotinamiento y en el uso de la violencia. Pero esta convicción y, sobre todo su práctica, entraban en contradicción con otras formas jurídicas o "legales" de lucha, usadas por la mayoría de los esclavos para acceder a la libertad. (Tovar, 1992, p. 13)

Pero si el negro abandonó las posibilidades legales de obtener la libertad, si se fugó, el riesgo de su huida lo llevaba, no hacia lo que sus amos e instituciones llamaban libertad y él aprendió a denominar de la misma manera. En rigor su resistencia, su huída, su rebelión, tuvieron como norte el recuperar todo aquello que le había sido negado al hacerlo esclavo. Esta recuperación cubre todo el período de la esclavitud, y se extiende hasta la contemporaneidad cuando el negro, por haber sido esclavo, debe sufrir prejuicios esclavistas que, de manera soterrada, persisten en el trasfondo de la discriminación.

Se puede invocar, como razón para abandonar el proceso de esclavización como preocupación académica, las conquistas logradas por los afrodescendientes con la abolición de la esclavitud en $1851^{4}$ y la Ley 70 de 1993 , resultado de la Constitución de 1991. Sin embargo debe recordarse que, como lo he sustentado en otros escritos, el proceso de abolición de la esclavitud a mitad del siglo XIX acabó siendo parcial e incompleta; se otorgó como libertad una ciudadanía para incorporarlos política y jurídicamente a la nación, mas no se concedieron condiciones de vida que le permitieran superar el sometimiento económico, social y cultural. La Ley 70 es la mayor conquista alcanzada por las comunidades afrocolombianas, pero su implementación ha sido entorpecida por problemas internos como por trabas burocráticas y por incorrectas interpretaciones de la norma.

El divorcio entre los desarrollos de los estudios afrocolombianos y la realidad socioeconómica de esta población, nos sugiere: que las formas de aproximación a las comunidades afro no son suficientemente adecuadas; que, tomando los aciertos de trabajos realizados, nos vamos acercando a una mejor comprensión de su historia, y que, es necesario explorar nuevos instrumentos para estudiar y profundizar en el proceso de sometimiento y liberación de la población afrodescendiente.

\footnotetext{
${ }^{4}$ La Ley de libertad de esclavos de 1851, no expresa la "abolición” de la institución esclavista; ordena por su parte que a partir de 1852 no habrán esclavos en el territorio de la Nueva Granada. " Art $^{\circ} 1^{\circ}$.- Desde el día primero de Enero de mil ochocientos cincuenta y dos serán libres todos los esclavos que existan en el territorio de la República. En consecuencia, desde aquella fecha gozarán de los mismos derechos y tendrán las mismas obligaciones que la Constitución y las leyes garantizan e imponen a los demás granadinos."
} 
Estos nuevos instrumentos deben estar pensados, obviamente con la preocupación por alcanzar nuevos niveles de comprensión de la trata negrera, la esclavización en América, los intentos de reducción del esclavizado a cosa y las luchas por su reivindicación de ser humano, hombre como todos los otros hombres. Para ello necesitamos adentrarnos en la averiguación por el significado que para el africano tuvo la captura y trata hacia América, desde su propia forma de ver el mundo; cómo esa trata modificó su percepción del mundo y por lo tanto sus parámetros de resistencia a los paradigmas de verdad que la cultura occidental le ofrecía.

Este objetivo, así planteado, requiere de una investigación amplia y profunda que no pretendemos abordar de inmediato, pero del que si podemos señalar que: iniciando por identificarlo como epistémico en dirección a obtener instrumentos metodológicos, requiere buscar los elementos paradigmáticos originarios y sus cambios hasta llegar a la construcción de nuevos paradigmas que lo guíen en las nuevas circunstancias americanas y le sirvan en la protección de su cultura.

\section{Bibliografía}

Arboleda S.J., José Rafael. (1952, Mayo) "Nuevas investigaciones afrocolombianas". En Revista Javeriana, Tomo XXXVII, (No. 184), pp. 9 - 19.

Barona Becerra, Guido. (1993). Legitimidad y Sujeción: los paradigmas de la "invención" de América. Bogotá: Colcultura.

Cabezas, Esteban. (1993). "Presencia lógica y poética del Muntu africano en la cultura americana". En Ulloa, Astrid (Comp.). Contribución africana a la cultura de las Américas (pp. 165 - 175). Bogotá: Instituto Colombiano de Antropología.

Cifuentes, Alexander [Ed.] (1986). La participación del negro en la formación de las sociedades latinoamericanas. Bogotá: Instituto Colombiano de Cultura.

Colmenares, Germán. (1979). Popayán: Una Sociedad Esclavista. 1680 - 1800. Bogotá: La Carreta.

Escalante, Aquiles (1971). La minería del hambre: Condoto y la Chocó Pacífico. Barranquilla: Tipografía Dovel

Escalante, Aquiles. (1964). El negro en Colombia. Bogotá: Universidad Nacional de Colombia.

Escalante, Aquiles. (1954). El Palenque de San Basilio. Barranquilla: Imprenta Departamental. 
Escalante, Aquiles. (1954). "El Palenque de San Basilio. Una Comunidad de Descendientes de Negros Cimarrones. Divulgaciones Etnográficas" En Instituto Etnográfico del Atlántico Vol. III, (No. 5).

Fals Borda, Orlando. (1980). Historia Doble de la Costa. Bogotá: Valencia Editores.

Finley CF, M.I. (1982). Esclavitud antigua e ideología moderna. Barcelona: Crítica.

Friedemann, Nina de \& Arocha, Jaime. (1986). De Sol a Sol. Bogotá: Planeta.

Friedemann, Nina de. (1993). La saga del negro. Bogotá: Instituto de Genética Humana, Pontificia Universidad Javeriana. Facultad de Medicina.

Friedemann, Nina de. (1979). Ma Mgombe. Bogotá: Valencia Editores.

Friedemann, Nina de. (1974). Minería, Descendencia y Orfebrería Artesanal, Litoral Pacífico. Colombia. Bogotá: Universidad Nacional de Colombia.

Gutiérrez de Pineda, Virginia. (1963). La Familia en Colombia. (Vol. 2). Bogotá: Universidad Nacional de Colombia.

Hernández de Alba, Gregorio. (1956). Libertad de los esclavos en Colombia. Bogotá: Editorial ABC.

Jaramillo Uribe, Jaime. (1986). "Los estudios afroamericanos y afrocolombianos. Balance y perspectivas." En Cifuentes, Alexander (Ed.). La participación del negro en la formación de las sociedades latinoamericanas. Bogotá: Instituto Colombiano de Cultura.

Jaramillo Uribe, Jaime. (1968). Ensayos sobre Historia Social Colombiana. Bogotá: Universidad Nacional de Colombia.

Meillasoux, Claude. (1990). Antropología de la Esclavitud. Bogotá: Siglo XXI.

Moreno Fraginals, Manuel. (1983). La historia como arma y otros estudios sobre esclavos, ingenios y plantaciones. Barcelona: Editorial Crítica.

Mörner, Magnus. (1979). Recent Research on Negro Slavery and Abolition in Latin America, Latin America Reprint (Series No. 15). Pittsburgh: Center for Latin American Studies, University of Pittsburgh.

Ortiz, Fernando. (1999). Contrapunteo cubano del tabaco y del azúcar (Advertencia de sus contrastes agrarios, económicos, históricos y sociales, su etnografía y su transculturación). Madrid: Edito CubaEspaña. 
Palacios Preciado, Jorge. (1988). La esclavitud de los africanos y la trata de negros. Tunja: Universidad Pedagógica y Tecnológica de Colombia.

Palacios Preciado, Jorge. (1973). La Trata de Negros por Cartagena de Indias. Tunja: La Rana y el Águila.

Price Jr. Thomas James, (1954). "Estado y necesidades de las actuales investigaciones Afro-colombianas" En Revista Colombiana de Antropología, Vol. II, (No. 2). pp. $11-35$.

Posada, Eduardo. (1933). La esclavitud en Colombia, Bogotá: Imprenta Nacional.

Restrepo Canal, Carlos. (1933). Leyes de Manumisión. Bogotá: Imprenta Nacional.

Sacco, José Antonio. (1932). Historia de la esclavitud de los indios en el Nuevo Mundo. (Vol. 2). Habana: Cultural, S. A.

Sacco, José Antonio. (1932). Historia de la esclavitud de la raza africana en el Nuevo Mundo y en especial en los países Américo-hispanos. (Vol. 2) Habana: Cultural, S. A.

Scelle, Georges. (1906). L'Asiento des negres. Paris: A. Pedone.

Sharp, William Frederick. (1976). Slavery on the Spanish Frontier. Oklahoma: University of Oklahoma Press

Tovar, Hermes. (1992). De una Chispa se forma una hoguera: Esclavitud, Insubordinación y Liberación. Tunja: Universidad Pedagógica y Tecnológica de Colombia, Publicaciones del Magíster en Historia.

Velásquez, Rogerio. (2000). Fragmentos de historia, etnografía y narraciones del Pacífico colombiano negro. Bogotá: Instituto Colombiano de Antropología e Historia.

Zapata Olivella, Manuel. (1993). "Afroamérica: Siglo XXI. Tecnología e Identidad Cultural", En Ulloa Astrid (Comp.), Contribución africana a la cultura de las Américas, Bogotá: Instituto Colombiano de Antropología.

Zapata Olivella, Manuel. (1989). Las claves mágicas de América, Bogotá: Plaza \& Janes.

Recibido: Octubre 19 de 2010

Aprobado: Mayo 9 de 2011 
